\title{
LA EDUCACIÓN CATÓLICA Y LA HISTORIA DEL EDUCADOR LAICO EN LA TRADICIÓN DE LA IGLESIA
}

\section{Juan Antonio Nureña *}

\section{LA EDUCACIÓN CATÓLICA}

P ara poder conocer y comprender el concepto de educación católica, es necesario, en primer lugar, conocer el concepto de «educación». A continuación, se anotarán algunas nociones preliminares.

Según el Diccionario enciclopédico de educación, «es un proceso mediante el cual se inculcan y se asimilan los aspectos culturales, morales y conductuales necesarios para ofrecer las respuestas adecuadas a las situaciones vitales con las que se encuentra el individuo, de forma que se asegura la supervivencia grupal y colectiva». Además, es un «hecho personal, porque supone la adquisición y perfección del individuo [...] es un proceso que se basa en el contacto humano, ya que hay una interacción entre educador y educando [...] la educación exige un posicionamiento activo de parte del educando, porque el individuo se construye a sí mismo a partir de la

* Licenciado en Filosofía y Religión por la Facultad de Teología Pontificia y Civil de Lima, con estudios en Sagrada Teología en la misma institución. Es docente del pregrado UCSS. 
orientación del educador, este es un proceso gradual que considera al individuo como unidad» (Martí 2000: 147).

En «La educación encierra un tesoro», Jacques Delors indica que «la educación es fundamental para el progreso de la humanidad» (1997: 17). Uno de los grandes desafíos de este nuevo siglo es poder enfrentar la grave crisis en Educación; por eso, existe hoy una emergencia educativa que se manifiesta a través de la cultura — proceso de humanización—, en donde el hombre tiene un origen y una meta como tal (cf. García Quesada 1992: 8).

En ese sentido, decía el Papa Juan Pablo II en su discurso a la UnEsco: «La cultura es aquello a través de lo cual el hombre, en cuanto hombre, "es” más, accede más al "ser". [...] La educación es parte de la cultura, porque la educación es uno de los medios a través del cual el hombre busca cultivarse (culturizarse) y genera, además, un ambiente específicamente humano» (1980: 7-9). En efecto, se considera la educación como parte de la trasmisión de la cultura:

[...] como una utopía necesaria, instrumento fundamental e indispensable para que la humanidad progrese hacia los ideales humanos de paz, de libertad y justicia social. En este sentido, la educación es un instrumento, una vía para conseguir un desarrollo humano más armonioso, más genuino, para hacer retroceder la pobreza, la exclusión, las opresiones, las guerras. La educación es además un instrumento de integración, ya que por ella el ser humano se integra en la sociedad en el lugar que le corresponde: en el educativo, en la familia, en la comunidad, en la nación. Sólo así la educación se convierte en una verdadera educación, encaminada a construir un mundo mejor, capaz de respetar los derechos del hombre y de la mujer, practicar el entendimiento mutuo y constituirse en un instrumento de promoción del género humano y no de discriminación. (Delors 1997: 17-18) 
Así pues, Delors también señala también que la educación como misión debe:

[...] permitir a todos sin excepción hacer fructificar todos sus talentos y todas sus capacidades de creación, lo que implica que cada uno pueda responsabilizarse de sí mismo y realizar su proyecto personal, lo cual será una contribución esencial a la búsqueda de un mundo más visible y más justo. En este sentido, para que el hombre pueda utilizar todas sus posibilidades se plantea y fomenta una educación durante toda la vida. Sólo así podrá ser uno competente frente a las exigencias de la realidad, podrá cooperar para el buen desarrollo de la sociedad que le fortalece y ser solidario, actitud que le une socialmente a los demás. (Delors 1997: 18)

En este discurso ofrece, además, los cuatro pilares para que la «utopía» necesaria de la educación pueda ser posible: «aprender a conocer, aprender a hacer, aprender a vivir y aprender a ser». Finalmente, para el autor, la educación del s. Xxi debe estructurarse en torno a estos cuatro pilares.

\section{1. Situación actual de la educación según las conferencias EPISCOPALES LATINOAMERICANAS}

Se conocerá, a continuación, la realidad de la educación en América Latina según los documentos de las conferencias episcopales latinoamericanas que han surgido en ella. 


\section{Documento de Medellín}

En primer lugar, este documento, que pertenece a la II Asamblea General de los Obispos Latinoamericanos, analiza los problemas que agobian a la realidad de América Latina en lo referente a la educación y considera la urgencia del desarrollo integral del hombre; el cual requiere de la capacitación y autoformación de las personas, como autores de su propio progreso, de una manera creativa y original, en un mundo cultural acorde con su propia riqueza y fruto de sus propios esfuerzos (cf. DM 1968: 4.2).

En segundo lugar, afirma que la educación latinoamericana está llamada a dar una respuesta al reto del presente y del futuro para nuestro continente; solo así será capaz de liberar a nuestros hombres de las servidumbres culturales, sociales, económicas y políticas, que se oponen a nuestro desarrollo (cf. DM 1968: 4.7). Además, se exige una educación liberadora, que convierta al educando en sujeto de su propio desarrollo para que de ese modo se libere de sus egoísmos. Señala, también, la necesidad de una educación creadora en todos sus niveles y abierta al diálogo para que de esa manera se pueda enriquecer con los valores que la juventud intuye y descubre como valederos para el futuro. Asimismo, se espera que este tipo de educación logre promover la comprensión entre los jóvenes, y entre estos y los adultos (cf. DM 1968: 4.8).

En tercer lugar, informa además que la Iglesia en su misión específica debe promover e impartir la educación cristiana —a la que todos los bautizados tienen derecho- para que alcance así la madurez de la fe. El documento exhorta a todos los maestros a tomar conciencia de la problemática de los estudiantes y a promover la auto-educación de los mismos. Su finalidad es formar una comunidad de educandos (cf. DM 1968: 4.11). 
Por último, plantea una educación integradora en la que se produzca una verdadera comunidad formada por todos e integrada dentro de la sociedad local. Además, debe estar abierta a la entidad nacional y latinoamericana, ser dinámica y viviente dentro de una oportuna renovación, y posibilitar el diálogo ecuménico. La escuela debe, por tanto, transformarse en el centro cultural, social y espiritual de la comunidad. Deberá partir de los hijos para llegar a los padres y a las familias, es decir, deberá partir de una educación netamente escolar para así llegar a los demás medios de educación (cf. DM 1968: 419).

\section{Documento de Puebla}

El documento de Puebla, facilitado en la III Asamblea General de los Obispos Latinoamericanos, señala que la educación es un punto importante para la evangelización de la Iglesia: «Para la Iglesia educar al hombre es parte integrante de su misión evangelizadora» (DP 1979: 1012). «Cuando la Iglesia evangeliza y logra la conversión del hombre, también lo educa, en la salvación [...] lejos de deshumanizar al hombre, lo perfecciona y ennoblece, lo hace crecer en humanidad. La evangelización es, en ese sentido, educación» (DP 1979: 1013).

Una de las amenazas que describe el documento de Puebla con respecto a la educación es que «la labor educativa se desenvuelve entre nosotros en una situación de cambio socio-cultural»; especialmente, en la «secularización de la cultura» (DP 1979: 1014). Además, Puebla señala que «la educación es una actividad humana del orden de la cultura» (DP 1979: 1024); de ese modo, subraya que la educación no es un simple proceso de información o de aplicación de técnicas que regulan habilidades, sino un proceso que se ubica dentro del ámbito cultural —es decir, en el ámbito de la humanización-, pues «la cultura tiene una finalidad esencialmente humanizadora» (DP 1979: 
1024). Por ello, señala el documento que «el objetivo de toda educación genuina es la de humanizar y personalizar al hombre, sin desviarlo, antes bien orientándolo eficazmente hacia su fin último» (DP 1979: 1024).

Por tanto, la educación, lejos de ser limitada a un ámbito privado o restricto, tiene el reto de colaborar decididamente en la construcción de una cultura y de un estilo de vida más conforme con la dignidad humana: «La educación humaniza y personaliza al ser humano cuando logra que éste desarrolle plenamente su pensamiento y su libertad, haciéndolo fructificar en hábitos de comprensión y en iniciativas de comunión con la totalidad del orden real. De esta manera el ser humano humaniza su mundo, produce cultura, transforma la sociedad y construye la historia» (DP 1979: 1025).

\section{Documento de Santo Domingo}

Este documento, producto de lavi Conferencia del Episcopado Latinoamericano, recalca la intencionalidad que debe tener la educación en la nueva evangelización: «La educación es un proceso dinámico que dura toda la vida de la persona y de los pueblos. Recoge la memoria del pasado, enseña a vivir hoy y se proyecta hacia el futuro. Por esto, la educación cristiana es indispensable en la Nueva Evangelización» (DSD 1992: 263).

En lo que concierne a los maestros, señala que ninguno de ellos educa sin saber por qué y para qué. Si se apuesta por una educación cristiana, esta debería consistir en la asimilación o la inculturación del Evangelio en la propia cultura. Por lo tanto, el maestro tiene que educar con la finalidad de estructurar un proyecto de hombre en el que viva Jesucristo; es decir, de formar un hombre cuyos valores estén concentrados en Él. «Si la educación tiene como fundamento y término a Cristo, entonces esta educación está recapitulando todo en Cristo y 
es una verdadera educación cristiana; si no, puede hablar de Cristo, pero no es cristiana» (DSD 1992: 265).

Por eso, el maestro cristiano debe ser considerado sujeto eclesial que evangeliza, catequiza y educa cristianamente, y que tiene además la identidad definida como laico comprometido; por tanto, su papel debe ser reconocido por la Iglesia. El docente identificado con los valores del evangelio brindará enseñanza sólida sobre la vida, el amor y la sexualidad; además, su función consistirá en corregir las desviaciones de ciertas informaciones ideológicas y convenidas que se reciben en las escuelas. En efecto, debe educar la libertad en el educando para que este pueda ser dueño de sus propios actos y ser también capaz de elegir el bien y luchar por el trabajo medio de formación en la virtud y santificación (cf. DSD 1992: 265).

\section{Documento de Aparecida}

El documento de Aparecida, realizado en la v Conferencia del Episcopado Latinoamericano, señala que la educación de América Latina está en riesgo y que existe una emergencia educativa. En este escrito, se menciona que las nuevas reformas educacionales — que se han dejado llevar por el cambio global - aparecen centradas principalmente en la adquisición de conocimientos y habilidades, dejando de lado o reduciendo el sentido antropológico de la persona. En ese sentido, se concibe la educación, preponderantemente, en función de la producción, la competitividad y el mercado (cf. DA 2007:328).

Por otra parte, se señala que en la educación de los países de América Latina se propicia la inclusión de factores contrarios a la vida, a la familia y a una sana sexualidad. Por lo tanto, en la educación de los jóvenes no se 
inculcan los mejores valores ni el espíritu religioso; tampoco se les enseña los caminos para superar la violencia y acercarse a la felicidad, ni se les ayuda a llevar una vida sobria y adquirir aquellas actitudes, virtudes y costumbres que harán estable el hogar que funden y que los convertirán en constructores solidarios de la paz y del futuro de la sociedad ${ }^{1}$ (cf. DA 2007: 328).

Ante esta situación, se afirma que la escuela está llamada a ser un «lugar privilegiado de formación y promoción integral, mediante la asimilación sistemática y crítica de la cultura, que se logra a través de un encuentro vivo y vital con el patrimonio cultural» (DA 2007: 329). Además, se señala que la cultura, para que sea educativa, debe insertarse en los problemas del tiempo en el que se desarrolla la vida del joven. A su vez, es una responsabilidad estricta de la escuela, como institución educativa, "poner de relieve la dimensión ética y religiosa de la cultura, con el fin de activar el dinamismo espiritual del sujeto y ayudarle a alcanzar la libertad ética que presupone y perfecciona a la función psicológica» (DA 2007: 330). El documento señala, además, que la finalidad de la educación consiste en motivar en el joven el deseo de responder a las aspiraciones más profundas del mundo contemporáneo; así la educación humanizará y personalizará al ser humano, haciendo que este desarrolle plenamente su pensamiento y su libertad. «De esta forma el ser humano humaniza su mundo, produce cultura, transforma la sociedad y construye la historia» (DA 2007: 330 y DP 1979: 1025).

1 Se recomienda analizar FC, 36-38. Además, es importante examinar los siguientes documentos: Juan Pablo II. Carta a la Familias. p. 13, 2 de febrero de 1994. Pontificio Consejo para la Familia. Carta de los derechos de la familia. Art. 5c, 22 de octubre de 1983. Pontificio Consejo para la Familia. Sexualidad humana, verdad y significado, Orientaciones educativas en familia. 8 de diciembre de 1995. 


\section{2. Concepto de escuela Católica y SU misión}

El término «escuela católica» deriva del término «escuela» — cuyo significado etimológico es 'lugar de enseñanza'- que proviene de la palabra latina schola. A su vez, este término deriva del griego skole ( $\sigma \chi \mathrm{o} \lambda \eta ́)$, que significa 'ocio', 'tiempo libre' o 'descanso' (este 'tiempo libre' solía dedicarse al estudio filosófico). Posteriormente, pasó a significar 'escuela' o 'estudio'.

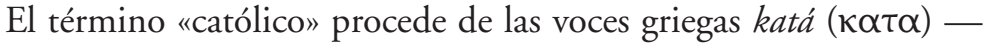
que significa 'enteramente', 'a lo largo de' o 'por' — y de holos (ódos) — cuyo significado es 'todo', 'entero' o 'completo'- La unión de ambos vocablos

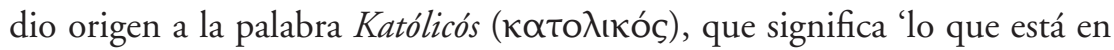
todas partes' o 'universal' (cf. Zamudio 2001: 29)

La escuela católica, en cuanto «escuela», comparte la naturaleza de la escuela en general. Como tal es «la institución de formación integral de la persona mediante la asimilación sistemática de la cultura» (Congregación para la educación católica 1982: 26). En la actualidad, se tiende a destacar más el aspecto comunitario de la escuela (cf. Congregación para la educación católica 1982: 11).

Los principales estamentos de la comunidad educativa de la escuela católica son los alumnos, los profesores y los padres de familia; también la integran el personal no docente y los representantes de la entidad promotora (cf. Congregación para la educación católica 1982: 11).

La misión de la escuela católica, como toda escuela, consiste en educar. Esa es su razón de existir; por eso, «persigue en no menor grado que las demás escuelas, los fines culturales y la formación humana de la juventud» (Declaración Gravissimum Educationis Momentum 1965: 8). Sin embargo, realiza su misión desde su específica identidad católica, es decir, desde dentro de una visión cristiana de la realidad (cf. Congregación para 
la educación católica 1997: 36), que tiene como centro y fundamento a Jesucristo.

El fin último de la escuela católica consiste en la formación integral del ser, que comprende la formación de su personalidad cristiana. Así, esta evangeliza educando y educa evangelizando (cf. Zamudio 2001: 33). Además, la escuela católica impulsa los valores humanos al educar a sus alumnos para que sean capaces de contribuir al bien de la sociedad y para que sirvan a la difusión del Reino de Dios entre sus contemporáneos. De este modo, la escuela católica gira en torno a la síntesis entre fe y cultura, y entre fe y vida (cf. Zamudio 2001: 33).

\section{3. El desafío de la Educación Católica}

Gracias a que la Congregación para la Educación Católica decidió erigir «la oficina para las escuelas católicas», se ha podido formar una misma línea de pensamiento, planteamiento y propuesta en torno a la educación católica: la educación o formación integral. Así, se entiende lo siguiente:

La formación integral del hombre, como finalidad de la educación, incluye el desarrollo de todas las facultades humanas del educando, su preparación para la vida profesional, la formación de su sentido ético y social, su apertura a la trascendencia y su educación religiosa. Toda escuela, y todo educador en ella, debe procurar "formar personalidades fuertes y responsables, capaces de hacer opciones libres y justas", preparando así a los jóvenes para abrirse progresivamente a la realidad y formarse una determinada concepción de la vida. (Congregación para la Educación Católica 1982: 17) 
Corresponde, por tanto, al educador tomar conciencia para guiar al educando:

[...] el educador católico está llamado a guiarse conscientemente en su tarea [...] concepción que, incluyendo la defensa de los derechos humanos, coloca al hombre en la más alta dignidad, la de hijo de Dios; en la más plena libertad, liberado por Cristo del pecado mismo; en el más alto destino, la posesión definitiva y total del mismo Dios por el amor. Lo sitúa en la más estrecha relación de solidaridad con los demás hombres por el amor fraterno y la comunidad eclesial; lo impulsa al más alto desarrollo de todo lo humano, porque ha sido constituido señor del mundo por su propio Creador; le da, en fin, como modelo y meta a Cristo, Hijo de Dios encarnado, perfecto Hombre, cuya imitación constituye para el hombre fuente inagotable de superación personal y colectiva. De esta forma, el educador católico puede estar seguro de que hace al hombre más hombre. (Congregación para la Educación Católica 1982: 18)

De esta manera, el desafío de la educación católica —en medio de un mundo en crisis de cultura y de valores- está en manos del educador laico, cuya misión de educar es oficio y función. Esta es la labor de ser profeta; por ello, ha de vivir y sentir su oficio como una misión y vocación. 


\section{EL EDUCADOR LAICO EN LA SAGRADA ESCRITURA Y EN LA TRADICIÓN DE LA IGLESIA A TRAVÉS DE LA HISTORIA}

\section{1. Evolución de LA Figura del EdUCAdor laico EN LA HiSTORIA²}

Para conocer ahora la figura del educador laico en la escuela es necesario conocer su historia. El desarrollo del educador laico, que se promovió en toda la historia, se produjo de forma creciente; aunque al inicio este desarrollo estaba totalmente clericalizado (sobre todo, a partir de la edad media e incluso desde el siglo $\mathrm{v}$ d. C.).

En la Edad media, ejercen un papel importante las escuelas catedralicias; es decir, los clérigos —únicos con cultura - enseñaban principalmente la doctrina cristiana y la visión cristiana del mundo.

Después del concilio de Trento, en toda la época del Barroco, se institucionalizó profundamente la enseñanza; por ello, se construyeron institutos que se dedicaban a esta. Las grandes órdenes religiosas buscaban también dedicarse a la educación.

En los siglos XVIII-XIX, con la aparición de grandes instituciones dedicadas a la enseñanza, se promovió que esta sea considerada un ministerio; es decir, un servicio a la humanidad. A partir de entonces, se consideró a la educación cristiana como un «servicio» por medio de dos aspectos:

a) La educación debe ser generalmente cristiana.

b) La educación estaba a cargo de los clérigos, mas no de los laicos A partir de la modernidad, se modifica la figura: aparece el proceso

2 Se sigue el esquema sobre la historia del educador católico de Dionisio Borobio en su obracatólica, Misión y ministerios laicales. 
de secularización y se producen cambios profundos, verificados en la segunda mitad del s. xx. Por ello, se verifica lo siguiente: «La enseñanza en las escuelas públicas se generaliza, los estados controlan esta enseñanza, en muchos casos es laica, no confesional; los centros religiosos cristianos pierden sus privilegios, los educadores cristianos vienen a ser laicos, en buena parte por necesidad; se exige que estos educadores asuman su vocación e identidad; para que su función responda a lo que demanda la Iglesia y la misma sociedad» (Borobio 2001: 118).

\section{El ministerio y CARISMas del educador laico desde en El Nuevo} Testamento

El ministerio del educador laico, desde el Nuevo Testamento, se centra en la figura de Cristo, el Maestro por excelencia, título que recibe por parte de sus discípulos: «¿Maestro, dónde vives?» (Jn 1, 35). El Señor presentó a sus discípulos esta tarea de educar como un mandato imperativo; así en San Marcos se puede apreciar lo siguiente: «vayan a todo el mundo y prediquen el Evangelio a toda criatura. El que crea y se bautice, se salvará; mas el que no crea, se condenará» (Mc 16, 15-16).

Por su parte, San Mateo recoge las siguientes palabras de Cristo: «Ir y enseñar a todas las gentes, bautizándolas en el nombre del Padre y del Hijo y del Espíritu Santo, enseñándolas a guardar todo lo que les he mandado. Yo estaré con ustedes hasta el fin del mundo» (Mt 28, 19-20). Son palabras que reproducen la continuidad del mandato de Cristo en la última cena: «Como Tú me enviaste al mundo, así los he enviado Yo al mundo» (Jn 17, 18). Este mandato solemne de Cristo — al anunciar la verdad salvadora — fue recibido por la Iglesia por medio de los Apóstoles, quienes le encomendaron llevarlo hasta el fin de la tierra. 
En Hechos 2, 42-47, se refleja cómo la Iglesia, desde sus orígenes, enseñaba y hacía más extensivo el cristianismo gracias a la primera comunidad cristiana. Sin embargo, la Teología de San Pablo es la que desarrolla mejor la doctrina del educador laico católico en el Nuevo Testamento y lo ubica en el rango de los carismas y ministerios en la Iglesia (cf. Borobio 1989: 154).

Por ello, la unidad en "un solo cuerpo" no se opone, sino que implica la unidad de los carismas (cf. 1Cor 12; Rom 12). Esta unidad en la pluralidad es, para San Pablo, un servicio o ministerio de la edificación común de la Iglesia. Señala, además, que todos los dones y carismas son necesarios y que cada uno contribuye, a su modo, con la edificación del Cuerpo de Cristo. Por tanto, nadie tiene derecho a apagar el don del Espíritu expresado en carismas; pero tampoco nadie tiene derecho a imponer sin respeto su carisma a los demás.

¿Cuáles son estos carismas que señala San Pablo? En diversos lugares, propone una lista de dones y carismas: de profecía, de curación, de hospitalidad y caridad (cf. Rom 12, 6-8; 1Cor 12, 28-29; Ef 4, 11-12). Estos tres casos se consideran los más importantes; entre ellos, está el ministerio del «Maestro» o «Doctor», del que «enseña»y del que «aconseja».

A su vez, en otros textos paulinos (cf. 1Cor 12, 28 y Ef 4, 11-12) existen varios aspectos que se deben tener en cuenta:

a) Que entre los carismas más importantes para la edificación del Cuerpo de Cristo se nombra a los que «han sido puestos para enseñar» (Rom 12, 7). También incluye a los «maestros o doctores» y a los «evangelistas y maestros»; lo cual indica la importancia que tenían.

b) Que se nombra este ministerio al mismo nivel y rango que el de los «pastores» o al de los «apóstoles y profetas», llevando una cierta dirección dentro de la comunidad. 
c) Que, por el contexto, se podría decir que San Pablo reconoce en estos carismas lo que hoy llamaríamos un verdadero «ministerio laical», reconocido en la primera comunidad, que supondría elección y significación ante la comunidad.

\section{El ministerio del educador laico desde la Sagrada Tradición}

En este apartado, se desea especificar dos testimonios importantes de la Iglesia primitiva: La Didaché y el de la Tradición apostólica de Hipólito (cf. Borobio 2001: 175).

\section{La Didaché}

Es un testimonio de finales del siglo I o principios del siglo Ir. En este, se nombran diversos ministerios, siguiendo al Nuevo Testamento. Entre ellos, se refiere de forma especial al de los «doctores»: les atribuye la función de enseñar e instruir; pero les advierte, también, que no deben enseñar falsas doctrinas. Por otra parte, se refiere a los falsos doctores en la misma línea (2Jn 1, 7-11), diciéndoles: «El que sobrepasa y no se queda dentro de la doctrina de Cristo, no posee a Dios. Si alguien llega a vosotros y no trae esta doctrina, no lo recibáis en vuestras casas, ni siquiera lo saludéis» (Borobio 2001: 175). 


\section{la Doctrina Apostólica de San Hipólito}

La Doctrina Apostólica de San Hipólito es un documento del s. III que nos describe de modo admirable la vida pastoral y litúrgica de los primeros siglos. En este trabajo, se encuentra la primera descripción detallada del Catecumenado. Así, al referirse a los ministerios que intervienen en el proceso del Catecumenado, nombra los siguientes: evangelizadores o padrinos, el «doctor audientium», los diáconos, los presbíteros y el obispo. Con respecto al doctor audientium, el texto le reconoce una función principal en la conducción catecumenal y, por lo tanto, en todo lo referente a la iniciación cristiana como educación en la fe. Además, dice que puede ser Klerós o laikós; es decir, puede ser clérigo o laico. También señala que sus funciones son diversas y se integran o complementan entre sí. Estas son las siguientes:

a) La instrucción o catequesis (katejein): Anuncio del Evangelio a los que escuchan.

b) La oración con los catecúmenos: Bendición, imposición de las manos y exorcismos.

c) La presentación ante la comunidad: La testificación de su vida.

d) El discernimiento: Si cambiaron de vida, si sirvieron a huérfanos y viudas.

\section{Conclusiones}

En conclusión, tras haberse analizado el concepto e importancia de la educación católica y de la historia del educador laico en la Sagrada Escritura y en la Tradición de la Iglesia, se descubre que, en primer lugar, es importante 
conocer y entender la educación católica en la actualidad por los siguientes motivos:

1. La educación latinoamericana está llamada a dar una respuesta al reto del presente y del futuro para nuestro continente, solo así será capaz de liberar a nuestros hombres de las servidumbres culturales, sociales, económicas y políticas que se oponen a nuestro desarrollo.

2. La educación católica puede enriquecer los valores que la juventud intuye y descubre como valederos para el futuro, y así puede promover la comprensión y el diálogo de los jóvenes entre sí, y de estos con los adultos.

3. Asimismo, la educación católica humaniza y personaliza al hombre sin desviarlo, orientándolo eficazmente hacia su fin último. La educación es un proceso dinámico que se produce durante toda la vida de la persona y de los pueblos. Además, recoge la memoria del pasado, enseña a vivir el presente y se proyecta hacia el futuro. Por esto, la educación cristiana es indispensable en la Nueva Evangelización.

4. Gracias a la educación, se manifiesta en el joven el deseo de responder a las aspiraciones más profundas del mundo contemporáneo; así la educación humaniza y personaliza al ser humano, haciendo que este desarrolle plenamente su pensamiento y su libertad. De esta forma, el ser humano humaniza su mundo, produce cultura, transforma la sociedad y construye la historia.

5. En cuanto a la misión específica de la Iglesia, esta debe promover e impartir la educación cristiana a la que todos los bautizados tienen derecho, para que estos puedan alcanzar la madurez de la fe. 
En segundo lugar, es importante conocer la historia del educador laico en la Sagrada Escritura y en la Tradición de la Iglesia; puesto que su papel actual es trascendental en la enseñanza e instrucción de los niños, jóvenes y adultos - es decir, tanto en las escuelas y centros superiores, como en institutos y universidades- De ese modo, se forman hombres que han de ser el futuro de nuestra humanidad. Por eso, se ha de justificar el papel, función y vocación del educador laico desde la Revelación y deseo de Dios, expresado tanto en la Sagrada Escritura como en la Tradición de la Iglesia. 


\section{SIGLAS Y ABREVIATURAS}

DA Documento de Aparecida. v Conferencia Episcopal Latinoamericana, 2007.

DM Documento de Medellín. in Conferencia Episcopal Latinoamericana, 1968.

DP Documento De Puebla. III Conferencia Episcopal Latinoamericana, 1979.

D SD Documento de Santo Domingo. iv Conferencia Episcopal Latinoamericana, 1992.

LG Lumen Gentium. Constitución Dogmática del Concilio Vaticano II sobre la Iglesia, Roma, 1964.

Vat II Documentos del Concilio Vaticano il. Constituciones. Decretos. Declaraciones, Roma, 1965. 


\section{BIBLIOGRAFÍA}

Borobio, Dionisio

2001 Misión y ministerios laicales. Salamanca: ed. Sígueme.

1989 Los Ministerios en la comunidad. Barcelona: ed. Centro de Pastoral. Litúrgica.

1987 Manual del cristiano comprometido. Madrid: ed. Sociedad de educación Atenas.

1982 Ministerio sacerdotal. Ministerios laicales. Bilbao: Desclée de Brouwer.

Delors, Jacques

1997 «La educación encierra un tesoro: informe a la UnESCO de la comisión internacional para el siglo XXI». En SÁnCHEZ Gutiérrez, Roy Abraham. Misión profética del educador católico laico. Lima: FTPCL.

García Quesada, Alfredo

1992 Educación y nueva evangelización. Lima: ODEC

Juan Pablo II

I980 «Discurso a la Unesco». París, 02 de Junio.

Martí, Isabel

2000 Diccionario enciclopédico de Educación. Barcelona: CEAC.

SÁnchez Gutiérrez, Roy Abraham

2000 Misión profética del educador católico laico. Lima: FTPCL. 
Zamudio Bustamante, Jorge

2001 El rol del profesor laico de la educación religiosa y el nuevo enfoque educativo peruano. Lima: FTPCL.

\section{DOCUMENTOS MAGISTERIALES}

Documentos del Concilio Vaticano iI

Constitución Dogmática Lumen Gentium, Roma, 1964.

Constitución Pastoral Gaudium et Spes, Roma, 1965.

Declaración Gravissimum Educationis Momentum, Roma, 1965.

Decreto Apostolicam actuositatem, Roma, 1964.

Decreto Ad Gentes, Roma, 1965.

\section{CONGREGACIONES}

CONGREGACIÓN PARA LA EDUCACIÓN CATÓLICA

1982 El laico católico, testigo de la fe en la escuela. Roma.

CONGREGACIÓN PARA LA EDUCACIÓN CATÓLICA

1997 La Escuela Católica. Roma.

PONTIFICIO CONSEJO PARA LA FAMILIA

1983 Carta de los derechos de la familia. Roma. 


\section{CONFERENCIAS EPISCOPALES}

il Coinferencia Episcopal Medellín, 1968.

ini Conferencia Fipiscopat. Pitfrita; ig7o

iv Conferenicia Episcopal Santo Domingo, i992.

v Conferencia Episcopal Aparecida, 2007. 